\title{
A ideologia do capitalismo nos movimentos sociais brasileiros: os "nós-do-governo"
}

\author{
Nadir Lara Junior* \\ Universidade de São Paulo, Instituto de Psicologia. São Paulo, SP, Brasil
}

Resumo: O objetivo deste trabalho é compreender os processos ideológicos presentes na relação entre o Estado brasileiro e movimentos sociais durante os governos Lula e Dilma até junho de 2013. Para isso, veremos que há alguns sujeitos que gozam quando aderem a todo aparato cínico presente na sociedade capitalista e ainda se identificam com esse modo de vida. Por outro lado, há sujeitos que se indignam com essa situação e buscam se organizar politicamente, neste caso em movimentos sociais. Tratamos sobre esses sujeitos que se organizam politicamente, porque eles também sofrem as investidas do Estado brasileiro que usa do engodo para colocá-los na lógica cínica de controle social capitalista. Nessa lógica, o engodo é uma formação discursiva que coloca em jogo uma dimensão simbólica e imaginária para tomar cinicamente o outro como objeto de sua satisfação.

Palavras-chave: psicanálise, engodo, discurso, capitalismo.

\section{Introdução}

Primeiramente, destacamos que este artigo decorre de uma apresentação no I Seminário de Psicologia Crítica realizado na Universidade de São Paulo (USP), em junho de 2013, portanto essa reflexão estava circunstanciada nesse momento histórico. Vivíamos, naquela ocasião, o furor das manifestações de junho daquele ano e tentávamos entendê-las. Nesse sentido, nosso objetivo neste artigo é compreender os processos ideológicos presentes na relação entre o Estado brasileiro e movimentos sociais durante os governos Lula e Dilma até junho de 2013.

Um dos aspectos que nos preocupava naquele momento era a relação que o Estado Brasileiro mantinha com os movimentos sociais até aquele momento histórico, e nos perguntávamos sobre a lentidão do governo federal e das câmaras (deputados e senadores) em dialogar com as demandas populares vindas das ruas. Sabemos que depois das manifestações de junho de 2013 muitas coisas mudaram no cenário político brasileiro, por exemplo, a organização de uma oposição ao Partido dos Trabalhadores (PT) e ao governo Dilma, até culminar com a aprovação, na Câmara dos Deputados, do pedido de impeachment da presidenta Dilma Rousseff em abril de 2016. Nós não trataremos disso nesse texto, porque estamos respeitando as circunstâncias históricas em que este foi escrito.

Veremos que a chegada do governo Luiz Inácio Lula da Silva (2003-2010) e Dilma Rousseff (20112014; 2015-2016) reposicionam no cenário político a relação do Estado Brasileiro com os movimentos sociais. Antes do estabelecimento desses governos, os movimentos se posicionavam antagonicamente ao

* Endereço para correspondência: nadirlj@hotmail.com
Estado, pois este se mostrava, muitas vezes, contrário aos interesses populares. Segundo Martins (2000), os militantes políticos e intelectuais desenvolveram recursos para questionar o Estado, mas não construíram estratégias para governá-lo. Esse choque de governança não se mostrou tão aparente, pois, no governo Lula, o Brasil possuía desenvolvimento social e econômico suficiente para não deixar transparecer a relação política do Estado com os movimentos organizados da sociedade civil.

$\mathrm{O}$ fato de o Brasil ter melhorado economicamente, durante o governo Lula e no primeiro governo Dilma (em 2011 nosso país era a sexta economia mundial ${ }^{1}$ ), e socialmente ${ }^{2}$, tornou-se possível, de certa maneira, porque vários militantes políticos foram trabalhar no governo, seja nos ministérios, como também nas assembleias ou fóruns. Isso trouxe o fortalecimento de diversas políticas públicas como veremos no decorrer deste trabalho.

Contudo, nessa relação do Estado com os militantes que estavam construindo as políticas públicas e desenvolvendo economicamente o país, algo desse "não estar preparado para governar o Estado", como nos diz Martins (2000), se manifesta por meio do significante "nós-do-governo" como uma espécie de engodo que atraía os militantes ao governo, muitas vezes sem críticas às formas como essa relação histórica estava se construindo. Todavia, na ocasião do I Seminário de Psicologia Crítica, tínhamos algumas hipóteses (que serão apresentadas na última parte deste artigo) dos desdobramentos desse engodo estabelecido entre Estado e movimentos sociais e parece que algumas delas se confirmam atualmente.

\footnotetext{
1 Recuperado de https://glo.bo/lcDcBna

2 Recuperado de https://bit.ly/2Hs6HVi
} 


\section{Engodo e sua formação discursiva}

No Dicionário Houaiss da língua portuguesa (Houaiss, 2001), "engodo" possui alguns significados. A primeira explicação desse dicionário sugere a metáfora do pescador que usa a isca para atrair o peixe. O engodo põe em jogo nessa metáfora dois elementos: sujeito que deseja capturar sua presa e, portanto, se utiliza de um artifício (isca) que reproduz os hábitos de alimentação da presa para atraí-la a seu objetivo, por isso a isca deve exercer certo fascínio para a presa. Segundo: o peixe, ao ser atraído por essa encenação, será capturado pelo anzol camuflado na isca. O resultante dessa operação é a satisfação do pescador e a captura do peixe.

A segunda definição diz que "engodo" significa "qualquer artifício para atrair alguém, chamariz" (Houaiss, 2001, pp. 1149-1150), portanto o artifício/chamariz cumpre a função de atrair alguém para um fim. Nessa relação, implicitamente, pressupõe-se que há um agente que arquiteta e administra a emboscada usando de subterfúgios para atrair outro alguém. Por outro lado, há aquele que será atraído por esse chamariz: o alvo da ação.

A terceira definição nos remete à ideia de uma "falsa atitude de lisonja, de adulação". Parece-nos que a definição vai se complementando, pois o artifício/ chamariz aqui é entendido como uma atitude de lisonja e adulação, no entanto efetuado de maneira falsa. A ação, portanto, se torna intencional, pensada e arquitetada como uma cilada (anzol e isca) para se conseguir algo/alguém. Já aquele que recebe essa ação, caso se deixe levar por essa lógica de ser adulado, acata a falsa lisonja como elogio, portanto, um equívoco "consentido".

Na quarta definição, o dicionário nos remete a "qualquer tipo de cilada, manobra ou ardil que vise enganar, ludibriar outrem, induzindo-o ao erro" (Houaiss, 2001, pp. 1149-1150). Novamente essa definição supõe uma relação de alguém que arma a cilada na intenção de capturar algum tipo de presa e, para isso, busca montar uma cilada que engane sua presa. Portanto, podemos supor ser uma relação em que uma desigualdade famigerada está posta: um é o peixe; outro é o pescador. $\mathrm{O}$ engodo é, portanto, o ato de enganar alguém com a colaboração do enganado.

Vemos ainda que essa exposição da palavra "engodo" constrói uma formação discursiva. Para Brandão (2004, pp. 106-107), formação discursiva é um conjunto de enunciados marcados pelas mesmas regularidades, pelas mesmas "regras de formação". Ela se define, portanto, por sua relação com a formação ideológica, isto é, os textos que fazem parte de uma formação discursiva remetem a uma mesma formação ideológica. A formação discursiva determina "o que pode e o que não pode ser dito" a partir de um lugar social historicamente determinado.

Em um mesmo texto podem aparecer formações discursivas diferentes, acarretando, com isso, variações de sentido em que há uma relação colocada entre o interpelador, que usa uma estratégia para seduzir, e o interpelado, que se deixa seduzir pela encenação (cilada) arquitetada pelo primeiro. No final dessa formação discursiva, o interpelador, quando captura o interpelado com suas ciladas, se beneficia de alguma forma com a aquisição, e o interpelado/presa, por sua vez, fica vulnerável às vontades daquele que o capturou.

\section{Engodo como formação discursiva insidiosa}

Diante dos aspectos apresentados até aqui, podemos perceber que os significados possíveis da palavra "engodo" não se resumem simplesmente a definições conceituais de um objeto, verbo ou comportamento, mas nos remetem a uma formação discursiva insidiosa que garante o pleno êxito das relações desmedidas nas posições de sujeitos estabelecidas nesse campo portanto, uma construção política posta no laço social, e não simplesmente um processo psicológico individual.

Vale notar que, ao buscarmos a etimologia de "engodo", descobrimos na língua portuguesa uma palavra para expressar uma situação política em que há posições não equivalenciais de sujeito, portanto não nos remete a uma casualidade ou a um mero equívoco mental individual. Assim, o engodo trata de uma questão política porque aponta para uma racionalidade operante no laço social em que as relações entre as pessoas são postas na lógica do opressor e do oprimido que se deixa "seduzir por falsas lisonjas" (Houaiss, 2001, pp. 1149-1150), aproximando-se da tese marxista de ideologia (Marx \& Engels, 2007).

Nesse sentido, o engodo como formação discursiva nos abre possibilidades para entender uma racionalidade inconsciente posta no laço social, pois aquele que arma o ardil e aquele que aceita morder a isca sustentam uma racionalidade cínica, já que participam da história sem se tornarem responsáveis pelo laço social que estruturam.

Dessa forma, Sloterdijk (2012) nos diz que na racionalidade cínica o sujeito não segue as normas convencionais de sociabilidade que regem uma determinada sociedade, pois, nessa racionalidade, aquele sujeito que detém certo poder nas relações convoca o outro para a posição de objeto, de coisa a ser usada. Nesse sentido, Safatle (2005) argumenta que o supereu, que deveria, de alguma forma, regular esse tipo de ação desproporcional, no capitalismo contemporâneo passa a se estruturar como um imperativo de gozo. Seguindo essa lógica, ao invés do sujeito se sentir culpado por não seguir as normas sociais e tomar o outro como coisa, goza pela satisfação de sua demanda imediata.

O cinismo, portanto, se configura como a "Lei sob a figura de um supereu que exige que as condutas sejam pautadas a partir da lógica do gozo puro" (Safatle, 2005, p. 134). Nesse sentido, o que impera é o apelo ao gozo irrestrito, e, assim, há cada vez menos, na sociedade capitalista, discursos que dizem o contrário ou que 
cerceiam esse imperativo de gozo, e consequentemente as instituições socializadoras permitem que essa ação cínica aconteça sem repressão - e assim passe a ser hegemônica e, por conseguinte, referencial identificatório para sujeitos "bem-sucedidos" no capitalismo.

Aqueles que aderem a essa interpelação se alienam do modelo político hegemônico, e, para que a alienação se justifique, a lógica do engodo oferece a esses sujeitos discursos ideológicos (dimensão simbólica) que justificam as relações desiguais como algo dado como partes constitutivas da vida em sociedade. Dessa maneira, mantém-se o status quo, porque os sujeitos participantes dessa montagem passam a assumir a não verdade como referente identificatório (dimensão imaginária) de suas vidas: non causa pro causa (Lara Junior, 2012).

O engodo é uma formação discursiva que coloca em jogo uma dimensão simbólica e imaginária para tomar cinicamente o outro como objeto de sua satisfação (pescador que pega o peixe); em termos políticos, verifica-se aí o não estabelecimento de relações equivalenciais, e, assim, constitui-se uma relação insidiosa. É insidiosa porque nessa formação discursiva há um sujeito na posição de interpelador cuja função é (re)montar uma encenação ardilosa destinada para o outro sujeito da relação com a finalidade de obter alguma vantagem às custas deste outro; complementarmente, há um sujeito interpelado que será convocado a atuar falsamente numa posição que mais lhe permite gozar cinicamente - supereu de gozo (Safatle, 2005; Žižek, 1999) - e dessa forma passa a achar "natural" sua situação de explorado. Também vale destacar que essa relação insidiosa não é absoluta, pois há aqueles que não se deixam interpelar com tal situação e lutam politicamente para revertê-la, como veremos mais à frente neste artigo.

Nesse sentido, poderíamos dizer que no engodo a função da ideologia é oferecer um mapa imaginário que define como naturais todas as posições de sujeitos a serem ocupadas no engodo (Elliot, 1998; Lara Junior \& Jardim, 2014). Esse mapa é passado, especialmente, no processo de socialização para que os sujeitos tratem essas posições desiguais e arbitrárias como parte da realidade que estão destinados a viver, e assim a ideologia assegura que as interpelações dos sujeitos que representam os interesses do capital tenham êxito. Dessa maneira, cria-se a fantasia ideológica do mundo almejado, como um "sentimento oceânico", ou até mesmo a fantasia da imutabilidade do laço social cujas coordenadas foram traçadas por um mapa ou qualquer outra entidade, perseverando assim um fatalismo sem possibilidades de mudança.

Nas palavras de Freud (1913/2005), no ritual totêmico, os filhos assassinavam o pai e realizavam o banquete imaginário no qual partes do pai eram distribuídas entre os filhos, e esses, por sua vez, se sentiam "como se fossem" o pai da horda em potencial - portanto, a isca "como se fossem" garante a eles a sensação de ser o próprio pai ou até mais poderosos que ele. Destacamos que, nessa montagem imaginária ("como se fosse") armada nos rituais totêmicos, o engodo é atualizado, pois os sujeitos participantes estão alienados.

Essa alienação dos sujeitos de si e da realidade cria uma situação desumana, de injustiça, opressão, crueldade, violência, miséria e outros sofrimentos evitáveis. Nesse sentido, a alienação aparece como desumana, pois priva o sujeito de sua razão e do conhecimento acerca da lógica dos meios de produção que o oprime:

A alienação arranca o sujeito de si mesmo, afasta-o de sua natureza real e de seus verdadeiros problemas. A alienação não está só nas ideias e sentimentos, mas na prática da exploração da classe trabalhadora. O trabalho se tornou alienado, escravizado e esmagador, pois faz o trabalhador se tornar refém de uma forma de trabalho que não o liberta da alienação, mas, ao contrário, o torna ainda mais preso à lógica da exploração de uma minoria (dona do capital) sobre a maioria. O peso da alienação faz com que os sujeitos tratem o dinheiro no sistema capitalista como entidade soberana e opressiva, e com isso mantém-se a lógica de exploração capitalista, porque ninguém ousa pensar uma economia que se organize sem a lógica do capital. O indivíduo alienado é lançado a destinos desumanos e, com isso, passa a tratar seu sofrimento como algo próprio de sua existência, como uma enfermidade de seu corpo, não visualizando nos modos de produção capitalistas as causas de muitos de seus sintomas. (Lara Junior, 2014, p. 108)

Nesse sentido Althusser (1970) afirma que a ideologia para se atualizar na sociedade capitalista necessita do ritual ideológico em que os sujeitos ficam alienados, por meio dos Aparelhos Ideológicos do Estado (AIE), participam ativamente e passam a ignorar o materialismo histórico para aderir a uma ideologia (como se fosse).

Assim, podemos citar um exemplo de alienação bastante presente em nossa realidade: um trabalhador assalariado que age "como se fosse" o dono do capital, atualizando assim o papel do "capitão do mato" da história da escravidão do Brasil, ou seja, o mestiço que não era negro, tampouco branco, mas tentava agir "como se fosse branco" mesmo que para isso precisasse ministrar a barbárie, sem culpa.

Retomamos a perspectiva de Freud (1913/2005) em Totem e tabu, a qual mostra, em um segundo momento, que o supereu (consciência moral) e o ideal de eu passam a representar as insígnias do pai. Nessa lógica, os filhos buscam na lei uma forma de garantir um suposto retorno do pai da horda, "como se fosse" o pai vivendo entre eles - identificação imaginária alienante. Assim apagam a culpa do assassinato e administram suas pulsões:

Tal é a dupla face da Lei ao representar o retorno do pai da horda: estabelece a culpa coletiva como 
princípio de organização social pela internalização dos impulsos agressivos, e institui a figura do "ideal do eu" que mantém os membros do grupo ligados libidinalmente entre si. A culpa, supereu coletivo, é, conforme Freud, o representante psíquico da pulsão de morte, e o laço libidinal, o representante da pulsão vida. (Poli, 2004, p. 42)

Pensamos que nessa identificação imaginária alienante busca-se a formação de uma horda primeva em que o pai permite aos filhos o gozo sem restrição; portanto, essa construção fantasiosa coloca em jogo os determinantes psicológicos do tabu (desejo inconsciente de violar a lei). Nesse sentido, os rituais e a magia alimentam crenças supersticiosas carregadas de desejos reprimidos. As cerimônias que cercam os tabus ajudam a disfarçar a hostilidade da lei (Freud, 1913/2005).

Nessa construção, a fantasia se torna uma estratégia para os sujeitos fugirem da realidade de insatisfação. Assim, se apropriam de discursos como o da religião, da psicologia e da psiquiatria, por exemplo, para que se sintam convencidos, em nome da ciência, de que devem se submeter/adaptar à lógica dos modos de produção capitalista (Lacan, 1992; Parker 2007).

Dessa maneira, apropriados dos discursos de verdade da ciência e da religião (Lacan, 2007), criam a montagem (imaginária e simbólica) para atrair e manter os que já estão na "cilada" de que esses sujeitos só poderão sobreviver sob seus auspícios - não há vida fora da horda primeva (Freud, 1913/2005) ou dos domínios do feudo, remontando a dialética do senhor e do escravo de Hegel. Só sobreviverão ao desemprego submetendo-se à lógica do capital, exposta por Marx (1968).

A partir desse raciocínio, pensamos com Freud que, para isso, os donos do capital montam uma encenação em que o pai da horda aparece "como se fosse" não castrado, e assim os sujeitos podem gozar cinicamente ignorando a culpa. Consequentemente, na sociedade capitalista torna-se possível o estabelecimento de um supereu que convoca os sujeitos a não reprimirem mais seus impulsos, e sim a realizá-los a qualquer custo. Para Safatle (2005), é Žižek quem traz essa inversão importante sobre a análise do supereu freudiano, que, nessa sociedade, convoca a autoridade paterna que não culpabiliza o prazer sexual e, portanto, não reprime nenhum tipo de gozo.

Para que essa relação superegóica se mantenha, todo conflito precisa ficar suspenso para, independentemente de qualquer normativo universal, imperar o apelo ao gozo irrestrito, sem considerar qualquer outra referência posta pelos processos de socialização. Como nos diz Marx (1968), o Estado passa a operar de maneira inequívoca na defesa dos interesses do capital, suspendendo qualquer ordem de conflito, mantendo o controle sobre os trabalhadores e fazendo-os produzir sem causar atritos (greves, reivindicações, questionamentos).

Portanto, o manejo feito pelo Estado em sua relação com os meios de produção capitalista não é mero equívoco, mas um engodo, porque supõe certa intencionalidade; porque arma a cilada (discurso capitalista do pai não castrado) para interpelar os que estão fora dessa lógica e para manter o controle sobre os que já foram "pegos". Desse modo, o engodo passa a operar numa racionalidade cínica:

Dessa maneira, no capitalismo o Outro é apresentado como um engodo, pois os capitalistas dizem ser esse não castrado, sem falta, onipotente, que tudo permite, e com isso "vende-se" a fantasia, por meio dos objetos de consumo, de que não há limite para o gozo. Como toda lógica capitalista, qualquer prestação de serviços tem um preço; dessa maneira, oferecer um "pai” não castrado que não regula mais a horda custa o abrir mão de um comprometimento do sujeito com seu desejo, ficando assim insaciavelmente numa demanda interminável. Essa construção é ideológica, pois existe uma dupla relação cínica. Daquele sujeito que vende o pai não castrado, pois, em última instância, ele sabe que há a castração, em segundo aqueles que compram e gozam na posição ilusória que possuem a opção de escolha. (Lara Junior, 2010, p. 71)

Seguindo o raciocínio do engodo como uma formação discursiva insidiosa, podemos nos perguntar: quem "vende" o pai não castrado? O que ganham com isso? Como conseguem isso? Como acontece essa formação discursiva para que obtenham êxito em nossa sociedade?

O engodo está em jogo na sociedade capitalista porque o dono do capital interpela o trabalhador como um despossuído de qualquer saber e poder. $\mathrm{O}$ discurso do capitalismo lança o ardil da construção fantasiosa de um lugar perfeito onde todos poderão gozar juntos. Nesse ponto não há espaço para crítica ou questionamento, e, portanto, a "isca" desse engodo é a crença em um mestre poderoso que sabe como livrar da angústia da falta e da incompletude. O produto dessas formações discursivas insidiosas é o esvaziamento da crítica e do questionamento, e com isso as ideologias mais absurdas podem se tornar a própria realidade dos sujeitos, pois assim conseguem justificar para os outros e ao Outro sua sina de subserviência.

Isso nos permite pensar que o engodo (ardil para conseguir a presa) pode funcionar como regra na relação do Estado com seus cidadãos e desses com seus pares. Nessa política estatal, permite-se que cada cidadão faça sua falsa lisonja para induzir o outro para sua armadilha, fazendo operar a racionalidade do engodo em seu pleno êxito, e assim todos podem gozar "como se fossem" o mestre ou o douto nas diversas instituições que já regulam essa forma de obtenção de gozo espúrio.

Seguindo esse raciocínio, no engodo a posição de interpelador não fica restrito ao dono capital - burguês descrito por Marx e Engels (1968) -, mas, por meio de uma política estatal de redistribuição de poder, os sujeitos 
assalariados tomados pelo engodo passam ardilosamente a interpelar seus pares, nessa mesma lógica insidiosa, para se sentirem parte do laço social. Com isso, a lógica do capital cumpre sua função de capilarizar poder para que uns dominem outros sem que necessariamente haja a figura clássica do burguês capitalista. Assim, os trabalhadores tomados por essa racionalidade passam a se tratar como nada, despossuídos, objetos de gozo imediato uns dos outros (Lara Junior, 2012).

Portanto, esse discurso do engodo se torna o referente identificatório na sociedade capitalista, e, para isso, cada vez mais os mestres e doutos estão investidos de saber e poder para determinar o engodo como regra de sociabilidade: "Goze no engodo!".

\section{O engodo dos "nós-do-governo"}

Vimos até aqui que há sujeitos que gozam quando aderem a todo o aparato cínico presente na sociedade capitalista e ainda se identificam com esse modo de vida. Por outro lado, há sujeitos que são historicamente oprimidos por essa racionalidade cínica por meio da pobreza, da miséria e de todos os tipos de abusos. Esses sujeitos, ao serem interpelados a atuar nessa racionalidade, não obtêm um gozo, mas sentem e percebem que estão diante de uma relação exploratória que causa sofrimento. Assim, indignam-se com essa relação e buscam se organizar politicamente, neste caso em movimentos sociais, justamente questionando a ordem social estabelecida (Lara Junior \& Jardim, 2014). Em contrapartida, sofrem as investidas do Estado brasileiro, que usa do engodo para colocá-los na lógica cínica de controle social capitalista.

Nessa mesma perspectiva, o nosso tempo político no Brasil é marcado a cada dia pela interpelação do Estado que, durante 500 anos, não abriu suas estruturas para a participação do cidadão e dos profissionais das diversas áreas. Agora, com a conquista da democracia e, consequentemente, a criação e a implementação de políticas públicas, cada vez mais cidadãos e profissionais estão se autorizando a se pôr em confronto e debate com as instituições estatais e seus burocratas. Nessa mesma onda, psicanalistas estão sendo convocados a participar do Estado, seja como funcionários públicos, como consultores ou como cidadãos. Portanto, faz-se mister debater essa relação.

Ao nos referirmos à relação dos movimentos sociais com o Estado brasileiro, estamos diante de uma questão polêmica e complexa devido ao fato desta ser de difícil circunscrição teórico-analítica e ainda uma discussão em voga a respeito do que seriam movimento social e o próprio Estado nos dias atuais, tendo em mente o desenvolvimento do sistema capitalista globalizado. No caso brasileiro, a questão ganha contornos específicos em virtude do processo histórico de formação do Estado, dos movimentos sociais e da relação estabelecida entre eles (Abers \& Bülow, 2011; Gohn, 2003; Moroni, 2005; Oliveira \& Silva, 2011; Rossiaud \& Scherer-Warren, 2000).
Para Martins (2000), o Estado brasileiro se estrutura para garantir às classes dominantes formas de controle social que legitimam privilégios. Uma das formas aplicadas pelo Estado para isso é o emprego da violência, que vai demonstrando às classes subalternas quais lugares sociais devem ocupar e que relações devem estabelecer com essa instância de poder - realidade que se acentuou com o estabelecimento da ditadura militar de 1964 a 1985, período em que o Estado demonstrou sua face autoritária de maneira mais explícita.

Nesse contexto, alguns movimentos sociais brasileiros começam a se estruturar na oposição a um Estado que historicamente privilegia uma classe social e que, portanto, utiliza os mais diversos aparatos de repressão para impedir que os militantes se aproximem de qualquer esfera decisória - esses eram tratados, em sua maioria, como comunistas, portanto uma ameaça ao Estado (Lara Junior, 2012).

Essa contingência, segundo Martins (2000), fez os movimentos tratarem o Estado como ameaça e, assim, construíam suas identidades coletivas nessa relação (necessária) de oposição e tentativa de tomada desse Estado. Nesse sentido, intelectuais e pesquisadores dos movimentos não percebiam outra possibilidade a não ser tratar o Estado como "inimigo", e, supostamente, não se prepararam para pensar como seria a atuação desses militantes após a abertura política e a redemocratização do país, que tiveram como marco a Constituição de 1988, assim como não imaginavam a tomada do poder por um partido que historicamente estava aliado aos movimentos sociais - no caso, o PT.

Vale destacar que a Constituição de 1988 foi o grande marco que garantiu e regularizou a participação dos atores sociais no processo de gestão do Estado, visto que este, antes tratado como inimigo, agora se preparava para ser a "casa do povo". Segundo Moroni (2005), a criação dos conselhos de gestão foi uma maneira encontrada para a população poder controlar o Estado, buscando assim criar espaços democráticos que garantissem a participação dos cidadãos. Foi essa participação efetiva dos movimentos que possibilitou a criação de conselhos e conferências como uma forma de participação e interferência na gestão dos recursos públicos:

Foi esse amplo movimento social e popular que elaborou a estratégia de criação do sistema descentralizado e participativo (conselhos e conferências) como instrumento de democratização e publicização do Estado. Vale ressaltar aqui a importância que tiveram neste processo os profissionais que atuavam no interior do Estado e que, em aliança com esse movimento, ajudaram na construção da estratégia política. (Moroni, 2005, p. 288)

Os movimentos que desde a década de 1980 começavam a se reestruturar no Brasil, não mais em função de classe social, mas de identidades coletivas 
marcadas por necessidades cidadãs, foram chamados pela literatura de novos movimentos sociais (Abers \& Bülow, 2011), justamente porque não estavam mais atrelados diretamente a sindicatos e partidos e porque suas causas eram contingenciais, tais como terra, casa, ecologia, gênero etc.:

O surgimento dos movimentos sociais, urbanos e rurais, fora de enquadramentos partidários, foi de certo modo uma grande novidade na sociedade brasileira, uma nova forma de expressão social que se combinou com o florescer de novos sujeitos sociais e políticos. As restrições partidárias viabilizaram a emergência de protagonistas do enredo histórico que o populismo das décadas anteriores havia sepultado na vala comum dos beneficiados antecipadamente pelo Estado provedor. Todas as demandas sociais ganhavam expressão e solução nas antecipações dos governantes e dos políticos. (Martins, 2000, p. 269)

Nesse contexto de redemocratização do país, os movimentos sociais se colocaram na (re)construção do Estado brasileiro democrático de direito; para isso, as políticas públicas ganharam destaque porque, de alguma forma, serviam como uma espécie de segurança legal para que uma causa social pudesse ser legitimada pelo Estado. Podemos dizer tranquilamente que muitas políticas públicas só existem no Brasil por força popular, como as de saúde, moradia, educação etc.

Outro fato a se destacar nesse contexto de redemocratização é a relação dos movimentos sociais com a Igreja Católica e as igrejas protestantes históricas, por meio de pastorais, e com os partidos políticos, especialmente o PT, o que Abers e Bülow (2011) e Oliveira e Silva (2011) denominaram de interpenetração partido-movimento. Isso possibilitou que muitos membros do PT ganhassem e assumissem cargos políticos nas mais diversas instâncias do Estado (conselhos, câmaras de vereadores, deputados, Senado, Governo etc.). Consequentemente, muitos militantes candidatos ou representantes de movimentos sociais subiram às instâncias instituídas de poder dentro do Estado e começaram a recrutar membros dos movimentos para trabalhos e funções burocráticas no corpo do Estado.

$\mathrm{Na}$ década de 1990, com o processo de reestruturação democrática em andamento, algumas políticas públicas importantes foram aprovadas, como o Sistema Único de Saúde (SUS), a Previdência Social etc., e, à medida que suas demandas eram reconhecidas pelo Estado, os militantes desses movimentos eram interpelados a participar da implementação de políticas ocupando cargos em conselhos e conferências (Moroni, 2005). Diante disso, os próprios movimentos, empurrados pela política neoliberal do Estado mínimo de Fernando Henrique Cardoso, tiveram de criar instituições legais, como organizações não governamentais (ONGs) e organizações de sociedade civil de interesse público (Oscips), para se enquadrar nas normas de editais de concorrência por verbas para implementação dessas políticas:

Aliás, as ONGs passaram a ter muito mais importância nos anos 90 do que os próprios movimentos sociais. Tratam-se de ONGs diferentes das que atuavam nos anos 80 junto com os movimentos populares. Agora são ONGs inscritas no universo do Terceiro Setor, voltadas para a execução de políticas de parceria entre o poder público e a sociedade, atuando em áreas onde a prestação de serviços sociais é carente ou até mesmo ausente, como na educação e saúde, para clientelas como meninos e meninas que vivem nas ruas, mulheres com baixa renda, escolas de ensino fundamental. (Gohn, 2003, p. 22)

Uma vez institucionalizados, os movimentos passaram a se organizar segundo as normas propostas pelo Estado (estabelecimentos dos fóruns e conferências), que por sua vez patrocinava financeiramente esses encontros. Com isso, as agendas dos movimentos passaram a receber influências dos funcionários do Estado, que lançavam suas necessidades e acabavam pautando as discussões em muitos grupos (Moroni, 2005).

Com o advento do governo Luiz Inácio Lula da Silva (2003-2010), os processos de interpenetração movimento-partido, participação de militantes em políticas públicas e seu consequente desenvolvimento de institucionalização se mostravam bastante encaminhados. Dessa maneira, muitos militantes passaram a ocupar cargos de confiança em vários níveis da burocracia estatal. Obviamente, o preenchimento desses espaços políticos facilitara muito a implementação de políticas públicas, e vários direitos básicos foram assegurados. A presença de militantes no Estado garantiu que algumas reivindicações desses grupos sociais fossem discutidas pelos governos:

O trânsito institucional se caracteriza pelo deslocamento contínuo de militantes sociais-partidários por diferentes espaços de atuação (organizações sociais, partidos, fóruns institucionais e posições governamentais), o qual é, em grande medida, possibilitado pela interpenetração partido-movimento. Assim, vitórias e derrotas eleitorais tendem a produzir um trânsito significativo de militantes da sociedade civil para o governo e vice-versa, gerando mudanças rápidas e intensas nas oportunidades de acesso institucional (tanto em termos de grau quanto em termos de forma). (Oliveira \& Silva, 2011, p. 98)

Para comprovar esse trânsito institucional e com base em Hochstetler, Oliveira \& Silva (2011) afirmam que, por exemplo, líderes da Central Única dos Trabalhadores (CUT) cederam seus quadros para cerca 
de nove ministérios e 53 secretarias de segundo e terceiro escalão. E poderíamos citar vários outros ministros que estavam diretamente ligados a alguma causa social:

A incorporação de ativistas no governo continuou no período mais recente. Por exemplo, no governo Lula, os dois ministros do Meio Ambiente (Marina Silva e Carlos Minc) tinham uma trajetória anterior de ativistas. A interpenetração de ativistas no Estado não é, entretanto, privilégio de "novos movimentos sociais", como o ambiental e o feminista. Esse fenômeno também ocorre entre ativistas da esquerda mais tradicional. (Abers \& Bülow, 2011, p. 67)

No entanto, não queremos negar o imenso avanço que tivemos em termos de políticas públicas e garantia de direitos, especialmente nos governos Lula e Dilma; destacamos aqui o Programa Bolsa Família, o Programa Universidade para Todos (Prouni), o Minha Casa Minha Vida, entre muitas outras políticas históricas no país. Porém até mesmo esses dois presidentes não tocaram na estrutura do Estado. É nesse ponto que reside nossa observação.

Nesse rendez-vous entre Estado e grandes grupos econômicos, ex-militantes começaram a sentir os reflexos de pertencer às oito maiores economias mundiais ${ }^{3}$, e muitas pautas dos movimentos sociais passaram a ser presididas por eles, que ganhavam alguns benefícios (status, bons salários, poder) por defender os interesses do Estado.

Nas pesquisas que realizamos, pudemos observar que esse tipo de militante que migrou para o Estado, supostamente representando interesses de movimentos sociais, durante muitas reuniões, conselhos e assembleias que organizavam passaram a se intitular "nós-do-governo". Ao se colocarem assim, buscavam conseguir a confiança dos militantes, para que esses não se mobilizassem contra o Estado, pois, nesse engodo, o movimento que se declarasse contra o Estado se declararia contra seus próprios "amigos", agora intitulados "nós-do-governo", portanto um "traidor" dos interesses comuns.

Destaco o significante - "nós-do-governo" -, que nos remete a duas ideias possíveis: a primeira, o "nós" funcionando como pronome pessoal, que nos remete à ideia de um grupo de pessoas que pertencem ao governo; e a segunda, o "nós" pode ser entendido como nó, ou seja, ato de amarrar, prender. Neste caso, podemos entender o "nós" como um engodo, porque nos mostra a ação do governo de amarrar os militantes a seus interesses e evitar assim a oposição. Também pode-se compreender o "nós" como um "laço" (armadilha) social para capturar a oposição e torná-la presa sob a burocracia do Estado, impedindo assim que os movimentos exerçam sua função necessária à democracia, de denúncia e de crítica ao sistema capitalista.

Pensamos que "nós" funciona como engodo, usado na primeira pessoa do plural, dando ideia de grupo, porque,

3 Recuperado de https://glo.bo/1cDcBna como já vimos, o Estado ainda não representa os interesses do povo - organiza-se em função do privilégio das elites -, tampouco deixa de fazer algo substancial pela população e pelos movimentos, a exemplo das políticas públicas. Nesse ponto surge um dilema: onde estariam as fronteiras políticas a que se refere Mouffe (1999) nessa relação entre movimentos sociais e Estado, que possibilitam a estruturação das identidades coletivas e, consequentemente, das disputas políticas entre amigos e adversários?

Nesse sentido, chamamos a atenção para o engodo de um Estado (interpelador) que se estrutura a partir dos espólios da pobreza, cujas estruturas estão pensadas para isso, visto que não houve na história do Brasil ruptura social e política com esse modelo; por outro lado, há os militantes e profissionais interpelados a participar desse Estado e que ficam fascinados por salário, estabilidade, poder, privilégios (isca). Novamente o resultado dessa operação de engodo é manter um Estado cinicamente equilibrado em sua função histórica: privilegiar uma classe social em detrimento de outras, e, para manter esse equilíbrio, é necessário que as escolas continuem sucateadas, os hospitais, em situação degradante, e que os estádios de futebol sejam luxuosos.

\section{Conclusão: o desatar dos "nós"}

A partir dos dados apresentados até aqui, podemos considerar que alguns sujeitos que participam desses movimentos são atraídos pelo discurso insidioso do Estado brasileiro, levando assim os movimentos sociais a enfrentar três grandes desafios: a) abandono da crítica e oposição em relação aos adversários políticos do Estado e as elites nacionais; b) especialização dos militantes em políticas públicas, que, assim, passam a trabalhar para o Estado sem manter o tensionamento político necessário para que mudanças estruturais possam ocorrer; e c) dificuldade de mobilizar as novas gerações para compor as lutas dos respectivos movimentos:

Ideologia opera no sentido de perpetuar a realidade existente. Assim, se a ideologia deixa lacunas na sua explicação generalizadora do mundo, é através destas brechas que é possível enxergar as contradições existentes e lutar por sua superação. E estas contradições, pertencentes à realidade, podem ser percebidas pela distância entre aquilo que é dito pela ideologia e aquilo que a realidade é. Assim a ideologia se esforça em coincidir com a realidade, colocando-se em seu lugar, mas porque o processo de adaptação é dialético, que não é contemplado por ela que grita por socorro, gerando o mal-estar. (Crochik, 1998, p. 2)

Nessa luta supomos que a principal estratégia usada pelo governo é produzir engodos que interpelam os sujeitos desses movimentos a partir de uma posição discursiva em que buscam capturá-los por uma ou mais estratégias 
de dominação para que o status quo permaneça em sua polaridade - uns dominando, outros sendo dominados:

Com a estruturação desse tipo de discurso, a opressão é dada como algo intrínseco à própria sociedade, como se essa fosse uma herança cultural, genética ou natural. A realidade é indistinguível da ideologia; perde-se a clareza da realidade e da ideologia, e com isso não se autorizam os sujeitos a se posicionarem diante da opressão que os assola. Assim, cabe ao sujeito cumprir as determinações ditadas pelo capitalismo como algo intrínseco ao processo de pertencer a uma sociedade. Dessa forma, os sujeitos ficam deslocados dos embates do cotidiano, dificultando-se qualquer possibilidade de mudança, pois passam a crer que a realidade está além das forças humanas e que tentar mudá-la está na ordem do impossível. (Lara Junior, 2012, p. 106)

Pensamos que os movimentos sociais, no atual contexto de nossa sociedade, são um dos principais responsáveis por expor o real da sociedade capitalista, e assim sustentam uma tensão necessária para a crítica da ideologia (Sloterdijk, 2003), pois são esses grupos organizados que sustentam uma oposição sistemática ao sistema capitalista:

Os movimentos contemporâneos são profetas do presente. Não têm força dos aparatos, mas a força da palavra. Anunciam a mudança possível, não para um futuro distante, mas para o presente da nossa vida. Obrigam o poder a tornar-se visível e lhe dão, assim, forma e rosto. Falam uma língua que parece unicamente deles, mas dizem alguma coisa que os transcende e, deste modo, falam para todos. (Melucci, 2001, p. 21)

Esses aspectos mostram com clareza que, nos dias de hoje, as lutas acontecem num campo simbólico, em que a distorção típica do capitalismo serve como manipulação ideológica universal. Nessa perspectiva, os movimentos sociais são fortemente interpelados pela ideologia capitalista, porque são eles que buscam contestar a lógica colocada na sociedade. É nesse campo de disputa política que os movimentos sociais são interpelados a participar dos engodos, para que assim se evite a denúncia das inconsistências e lacunas do sistema capitalista operando nas diversas formas de gestão do Estado brasileiro.

Em abril de 2016, percebemos que nossa hipótese de 2013, de que os engodos do Estado em relação aos militantes dos movimentos sociais resultaram no enfraquecimento de uma política de oposição histórica (em geral liderada pelos movimentos sociais) às elites nacionais e ao próprio Estado, culminou no abatimento do governo Dilma e na reorganização de um tipo de política que flerta com antigos sistemas autoritários, como o militarismo, por exemplo.

\title{
The ideology of capitalism in Brazilian social movements: the "nós-do-governo"
}

\begin{abstract}
The aim of this work is to understand the ideological processes in the relationship between Brazilian State and social movements during Lula and Dilma Rousseff Governments until June 2013. For this purpose, we will see that there are some subjects that enjoy themselves when join any cynical apparatuses in the capitalist society, and also identified themselves with this lifestyle. On the other side, there are subjects that are indignant with this situation and seek to politically organize themselves, in this case in social movements. The article discusses these politically organized subjects, since the Brazilian State uses the "engodo" to put them in the cynical logic of capitalist social control. In this logic, the "engodo" is a discursive formation that puts at stake a symbolic and imaginary dimension for one to take cynically the other as object of his satisfaction.
\end{abstract}

Keywords: psychoanalysis, Marxism, "engodo", discourse, capitalism.

\section{L'idéologie du capitalisme dans les mouvements sociaux brésiliens : les “nós-do-governo"}

Résumé: Le but de ce travail est de comprendre les processus idéologiques présents dans la relation entre l'État brésilien et les mouvements sociaux pendant le mandat gouvernemental de Lula et Dilma jusqu'à juin 2013. Pour cela, nous verrons qu'il y a quelques personnes qui extrapolent quand elles adhèrent à toute méthode cynique présente dans la société capitaliste et s'identifient même avec ce mode de vie. Nous traitons dans cet article de ces sujets qui s'organisent politiquement, parce qu'ils souffrent aussi des assauts de l'État brésilien qui utilisent des pièges pour les mettre dans la logique cynique de contrôle social capitaliste. Dans cette logique, le piège est une formation discursive qui met en jeu une dimension symbolique et imaginaire pour prendre cyniquement l'autre comme objet de sa satisfaction.

Mots-clés: psychanalyse, engodo, discours, capitalisme. 


\section{La ideología del capitalismo en los movimientos sociales brasileños: los “nós-do-governo”}

Resumen: El objetivo de este trabajo es entender los procesos ideológicos en la relación entre el Estado brasileño y los movimientos sociales durante el gobierno Lula y Dilma hasta junio de 2013. Con este fin, veremos que hay algunas personas que gozan cuando se adhieren a todos este aparato cínico en la sociedad capitalista y todavía identificanse con esta forma de vida. Por otro lado, hay personas que están indignados con esta situación y tratan de organizarse políticamente, en este caso los movimientos sociales. Acerca de esos tipos que se organizan políticamente es que vamos tratar en este artículo, ya que también sufren la embestida del estado brasileño que utiliza "engodo" para ponerlos en la lógica cínica de control social capitalista. En esta lógica, el "engodo" es una formación discursiva que pone en juego una dimensión simbólica e imaginaria que toma cínicamente el otro como el objeto de su satisfacción.

Palabras clave: psicoanálisis, engodo, discurso, capitalismo.

\section{Referências}

Abers, R. \& Bülow, M. (2011). Movimentos sociais na teoria e na prática: como estudar o ativismo através da fronteira entre estado e sociedade? Revista Sociologias, 13(28), 52-84. Recuperado de https://bit.ly/2vDWBL9

Althusser, L. (1970). Ideologia e aparelhos ideológicos do Estado. Lisboa, Portugal: Presença.

Brandão, H. N. (2004). Introdução à análise do discurso. Campinas, SP: Editora Unicamp.

Crochik, L. (1998). Os desafios atuais do estudo da subjetividade na psicologia. Revista Psicologia USP, 9(2), 69-85. Recuperado de http://dx.doi.org/10.1590/ S0103-65641998000200003

Elliot, A. (1998). Teoría social y psicoanálisis en transición: sujeto y sociedad de Freud a Kristeva. Buenos Aires, Argentina: Amorrortu.

Freud, S. (1993). Psicología de las masas y análisis del yo. In Obras completas: más allá del principio de placer, psicología de las masas y análisis del yo, y otras obras (1920-1922) (J. L. Etcheverry, trad., Vol. 18, pp. 65-136). Buenos Aires, Argentina: Amorrortu. (Trabalho original publicado em 1921)

Freud, S. (2005). Totem e tabu. Rio de Janeiro, RJ: Imago. (Trabalho original publicado em 1913)

Gohn, M. G. (2003). Movimentos sociais na atualidade: manifestações e categorias analíticas. In M. G. Gohn (Org), Movimentos sociais no início do século XXI: antigos e novos atores sociais (pp. 20-36 ). Petrópolis, RJ: Vozes.

Houaiss, A. (2001). Dicionário Houaiss da língua portuguesa. Rio de Janeiro, RJ: Objetiva.

Lacan, J. (1992). O seminário, livro XVII: o avesso da psicanálise, 1970. Rio de Janeiro, RJ: Zahar.

Lacan, J. (2007). Do símbolo e de sua função religiosa. In J. Lacan, O mito individual do neurótico, 1954. Rio de Janeiro, RJ: Zahar.

Lara Junior, N. (2010). Mística como laço social: um estudo psicanalítico. A Peste: Revista de Psicanálise e Sociedade e Filosofia, 2(1), 113-141. Recuperado de https://revistas.pucsp.br/index.php/apeste/article/view/ $12078 / 8751$
Lara Junior, N. (2012). A verdade em tempos de Ditadura Militar: reflexões a partir da psicanálise. Revista Ciências Sociais Unisinos, 48(2), 103-110. doi: 10.4013/ csu.2012.48.2.04

Lara Junior, N. (2014). Violência e ideologia: os humilhados serão exaltados?. In S. Viola(Org.), Sociologia da educação (pp. 102-110). São Leopoldo, RS: Editora Unisinos.

Lara Junior, N. \& Jardim, L. (2014). Aporte psicoanalítico para el análisis de los lugares discursivos e ideológicos. Revista Teoría y Crítica de la Psicología, 4, 60-77. Recuperado de https://bit.ly/2M91hlv

Martins, J. S. (2000). As mudanças nas relações entre a sociedade e o Estado e a tendência à anomia nos movimentos sociais e nas organizações populares. Revista Estudos Avançados, 14(38), 268-278. Recuperado de https://bit.ly/2JEck7Z

Marx, K. (1968). El capital: crítica de la economía política (Vol. 1). Buenos Aires, Argentina: Fondo de Cultura Económica.

Marx, K. \& Engels, F. (2007). A ideologia alemã: crítica da mais recente filosofia alemã em seus representantes Feuerbach, B. Bauer e Stirner, e do socialismo alemão em seus diferentes profetas. São Paulo, SP: Boitempo.

Melucci, A. (2001). A invenção do presente: movimentos sociais nas sociedades complexas. Petrópolis, RJ: Vozes.

Moroni, J. A. (2005). O direito à participação no Governo Lula. Revista Saúde em Debate, 29(71), 284-304. Recuperado de https://bit.ly/2Lz60fx

Mouffe, C. (1999). El retorno del político comunidad, ciudadanía, pluralismo, democracia radical. Barcelona, España: Paidós.

Oliveira, G. L. \& Silva, M. K. (2011). A face culta(da) dos movimentos sociais: trânsito institucional e intersecção Estado-Movimento: uma análise do movimento deEconomia Solidária no Rio Grande do Sul. Revista Sociologias, 13(28), 86-124. Recuperado de https://bit.ly/2iDKGvJ

Parker, I. (2007). Revolution in psychology. London, England: Pluto Press.

Poli, M. C. (2004). Perversão da cultura, neurose do laço social. Revista Ágora, 7(1), 39-54. Recuperado de https://bit.ly/2kUUIGU 
Prado, M. A. M. (2001). Psicologia política e ação coletiva: notas e reflexões acerca do processo de formação identitária do 'nós'. Revista Psicologia Política, 1(1), 149-172. Recuperado de https://bit. ly/2M9y7CLQuinet, A. (2009). A estranheza da psicanálise: a Escola de Lacan e seus analistas. Rio de Janeiro, RJ: Zahar.

Rossiaud, J. \& Scherer-Warren, I. (2000). A democratização inacabável: as memórias do futuro. Petrópolis, RJ: Vozes.

Safatle, V. (2005). Depois da culpabilidade: figuras do supereu na sociedade de consumo. In C. Dunker, \& J. L. A. Prado, Zizek crítico: política e psicanálise na era do multiculturalismo (pp. 119-140). São Paulo, SP: Hucitec.
Sloterdijk, P. (1999). Como Marx inventou o sintoma? In S. Žižek (Org.), Um mapa da ideologia (pp. 297-331). Rio de Janeiro, RJ: Contraponto.

Sloterdijk, P. (2003). Bem-vindo ao deserto do Real: cinco ensaios sobre o 11 de setembro e datas relacionadas. São Paulo, SP: Boitempo.

Sloterdijk, P. (2012). Crítica da razão cínica. São Paulo, SP: Estação Liberdade.

Žižek, S. (1999). O espectro da ideologia. In S. Žižek (Org.), Um mapa da ideologia (pp. 7-38). Rio de Janeiro, RJ: Contraponto.

Recebido: 20/12/2016

Aprovado: 31/05/2018 